\title{
Gastric Juice Prostaglandins and Peptide Growth Factors as Potential Markers of Chronic Atrophic Gastritis, Intestinal Metaplasia and Gastric Cancer: Their Potential Clinical Implications Based on this Pilot Study
}

\author{
Ajoy Dias · Cesar Garcia • Marek Majewski • \\ Grzegorz Wallner • Richard W. McCallum • \\ Cezary Poplawski $\cdot$ Jerzy Sarosiek
}

Received: 25 August 2010/Accepted: 14 May 2011/Published online: 22 June 2011

(C) The Author(s) 2011. This article is published with open access at Springerlink.com

\begin{abstract}
Background Gastric secretion can provide valuable information especially when Helicobacter pylori $(\mathrm{Hp})$ infection results in chronic atrophic gastritis (CAG) and intestinal metaplasia (IM) preceding adenocarcinoma (AdCa).

Aims Looking for a potential biomarker of malignant transformation in the setting of chronic inflammation we studied the levels of prostaglandin E2 $\left(\mathrm{PGE}_{2}\right)$, as well as peptide growth factors [epidermal growth factor (EGF) and transforming growth factor $\alpha(\mathrm{TGF} \alpha)$ ], harbingers of injury and repair, in gastric juice aspirated at endoscopy from patients with CAG, CAG/IM, AdCa, and controls.

Methods The $\mathrm{PGE}_{2}, \mathrm{EGF}$ and TGF $\alpha$ concentrations in the gastric juice were measured using radioimmunoassays (RIAs). Results In patients with $\mathrm{AdCa}$ gastric juice $\mathrm{PGE}_{2}$ increased fivefold versus controls $(P<0.01)$ and almost threefold versus patients with CAG $(P<0.05)$. The EGF levels in patients with AdCa were fourfold higher versus controls $(P<0.001)$ and almost threefold higher versus CAG $(P<0.05)$. In patients with CAG/IM the EGF levels were also almost 3 times higher versus controls. The TGF $\alpha$ levels in patients with AdCa were half the value of controls and CAG $(P<0.05)$. In patients with $\mathrm{CAG} / \mathrm{IM}$ the levels were as low as $1 / 5$ of controls or CAG $(P<0.05)$.
\end{abstract}

\footnotetext{
A. Dias · C. Garcia · R. W. McCallum · J. Sarosiek ( $\square)$ Department of Internal Medicine, TTUHSC Paul L. Foster e-mail: jerzy.sarosiek@ttuhsc.edu

M. Majewski · G. Wallner

Medical University of Lublin, Lublin, Poland

C. Poplawski

Collegium Medicum, UMK, Bydgoszcz, Poland
} School of Medicine, Texas Tech University Health Sciences Center, 4800 Alberta Avenue, El Paso, TX 79905-2709, USA
Conclusions Testing the gastric juice for $\mathrm{PGE}_{2}, \mathrm{EGF}$, and $\mathrm{TGF} \alpha$ in patients with endoscopy and biopsy proven CAG, may be helpful in follow up of patients who may potentially progress to IM and ultimately AdCa. This could be considered as an adjunct to histologic assessment especially that even the best surveillance biopsy specimen regimens are inherited with sampling errors.

Keywords Gastritis - Intestinal metaplasia . Adenocarcinoma $\cdot$ Helicobacter pylori . Prostaglandins $\cdot$ Peptide growth factors

\section{Introduction}

The integrity of the gastrointestinal mucosa depends upon equilibrium between aggressive factors and protective mechanisms [1-3]. Among aggressive factors gastric acid and pepsins are the culprits of injury, whereas $\mathrm{PGE}_{2}$ and peptide growth factors such as EGF and TGF $\alpha$ are the dominant protective molecules [4-8].

Colonization of gastric mucosa with $H p$ profoundly changes this equilibrium mainly through generation of acute and subsequently chronic inflammation and secretion of its toxins and various enzymes [4-8].

The concentration of $\mathrm{PGE}_{2}, \mathrm{EGF}$ and $\mathrm{TGF} \alpha$ in the gastric juice reflects the rate of the production by the gastric mucosa, their subsequent binding to the receptors on the luminal aspect of the surface epithelium and their proteolytic degradation by gastric acid and pepsin as well as enzymes generated by $H p$ [9].

The aggressive factors induced gastric mucosal injury resulting in loss of mucosal barrier can be quickly healed if adequate supply of $\mathrm{PGE}_{2}$, EGF and $\mathrm{TGF} \alpha$ takes place. Therefore the measurement of PGE2, EGF and TGF $\alpha$ in the 
gastric juice could reflect their availability for restitution of injured cell epithelium and repair as well as restoration of the mucosal barrier. This is especially an important consideration given the fact that within the gastric mucosal milieu there is always a very powerful and protective endogenous barrier against the aggressive factors especially acid and pepsin [9]. We have therefore studied the concentration of $\mathrm{PGE}_{2}$, EGF and $\mathrm{TGF} \alpha$ in gastric juice aspirated at the onset of surveillance endoscopy in patients colonized with $H p$ in the past with subsequent CAG, IM and gastric $\mathrm{AdCa}$ and compared the levels with those with $H p$ negative controls. This way we have utilized a sample of gastric juice, which would have been discarded otherwise.

Our data represent a proof of concept that the concentrations of PGE2, EGF, or TGF $\alpha$ may differ at various stages of gastric mucosal pathology related to the past history of colonization with $H$. pylori.

\section{Materials and Methods}

\section{Subjects}

The study was approved by the Human Investigation Committee at KUMC. Informed consent was obtained from all subjects. Twenty eight consecutive patients referred for upper GI endoscopy for surveillance and with symptoms of non-ulcer dyspepsia were enrolled in the study. All patients had $H p$-induced CAG or CAG/IM or CAG/IM/AdCa as confirmed by the endoscopy and gastric biopsy, although they received $H p$ eradication. Successful $H$. pylori eradication was confirmed by ${ }^{14} \mathrm{C}$-urea breath test.

Among recruited patients 16 were $\mathrm{M}$ and $12 \mathrm{~F}$. Of the 28 subjects 11 had CAG (6 M \& 5 F), 8 had CAG/IM ( $5 \mathrm{M} \& 3 \mathrm{~F})$ and 9 patients had Gastric AdCa ( $5 \mathrm{M} \& 4 \mathrm{~F})$. The mean age of the population was 55 years (range 30-65 years). There were $13 \mathrm{Hp}$ negative controls with symptoms of non-ulcer dyspepsia (7 M \& $6 \mathrm{~F}$, mean age of 52, 28-64 range) with normal endoscopy and histology.

All subjects represent outpatient's population within the Endoscopy Center. Patients were advised not to eat and drink after midnight. Patients were not taking non-steroidal anti-inflammatory drugs as well as antisecretory medication for at least 1 week before endoscopy. All patients were prepared for endoscopy using the same standardized procedure. None medication, including antacids, was allowed on the day of endoscopy.

The biopsy sampling and degree of gastritis was assessed according to Sydney System, 1996. Briefly, 1 specimen was obtained from the lesser and 1 from the greater curvature of the antrum, both within $2-3 \mathrm{~cm}$ from the pylorus;
1 sample from the lesser curvature of the corpus approximately $4 \mathrm{~cm}$ proximal to the angulus, 1 sample from the middle portion of the greater curvature of the corpus, about $8 \mathrm{~cm}$ from the cardia and 1 sample from the incisura angularis".

Even more than 1 year after successful $H$. pylori eradication, in a great majority of patients at least moderate infiltration with chronic inflammatory cells was recorded and was similar in three investigated groups. Atrophy of the gastric body mucosa was defined as focal or diffuse oxyntic gland loss and/or replacement by metaplastic pyloric or intestinal glands. Atrophy of the gastric antral mucosa was defined as focal or complete replacement of antral glands with intestinal metaplastic epithelium. Presented patients with gastritis were diagnosed as moderate or severe gastritis with or without type III of intestinal metaplasia.

The age, gender and the smoker status distribution was similar in all subgroups and none of them were drinking more than 1-2 drinks per day. H. pylori eradication was implemented at least 1 year ago. Gastric cancer was found on the lesser curvature and around the angulus, measured between 2 and $5 \mathrm{~cm}$ and histologically represented the intestinal type of adenocarcinoma, T1 or T2, all well or moderately well differentiated.

At the time of endoscopy gastric juice present within the stomach was aspirated into a container, iced, assessed volumetrically and processed immediately.

All samples were centrifuged at 3,000 rpm $(2,500 \mathrm{~g})$ for $30 \mathrm{~min}$, conditions required to spin down cell debris such as plasma membrane sheets and nuclei (Sorvall RT 6000 Refrigerated Centrifuge, Rotor H1000, Newtown, CT). All samples were centrifuged at $4^{\circ} \mathrm{C}$.

\section{Methods}

\section{Measurement of $\mathrm{PGE}_{2}$}

$\mathrm{PGE}_{2}$ in the gastric juice was measured as the methyloxime by the radioimmunoassay (RIA) using a novel iodinated label (Amersham, Arlington Heights, IL) developed by Kelly et al. [10] as described recently [11, 12]. The advantage of this method is that the imide linkage of the methyl oxime to proline results in an equal affinity of antiserum for the labeled oximated $\mathrm{PGE}_{2}$ and compound to be measured. Methyloximation also protects $\mathrm{PGE}_{2}$ from dehydration during the assay. The sample extraction step through C18 columns provides a high degree of homogeneity and it also maintains near $100 \%$ recovery of added $\mathrm{PGE}_{2}$. We achieved very good intraassay (3.4\%) and interassay $(5.8 \%)$ variations [11]. 


\section{Measurement of EGF and TGF $\alpha$}

The $\mathrm{pH}$ of gastric secretion was recorded with an expandable Ion Analyzer (model AE 940; Orion, MA) and $\mathrm{pH}$ of gastric juice was adjusted to $\mathrm{pH} 7.4$ before the measurement of EGF and TGF $\alpha$. Measurements of EGF and TGF $\alpha$ were performed by RIA using a commercially available kit (Amersham, IL). This assay is based on the highly specific rabbit anti-human RGF and TGF $\alpha$ antibodies, which do not exhibit cross-reactivity with a large variety of structurally unrelated gut peptides such as gastrin, somatostatin, secretin, or pancreatic polypeptide [7, 8].

Anti-human EGF and TGF $\alpha$ antibodies showed an $88 \%$ cross reactivity with the mouse EGF but not rat TGF $\alpha(0 \%$ cross-reactivity). Human EGF antiserum was used at a dilution of 1:20,000. The separation between bound and unbound EGF was performed with a use of Amerlex-M second antibody. In the final calculations of EGF and TGF $\alpha$ concentrations, non specific binding was always considered. Human recombinant EGF (Amgen, CA) was used for a standard curve.

\section{Statistical Analysis}

All results are presented as the mean \pm SEM. Statistical analysis of variance (ANOVA) was performed using Sigma-Stat (Jandel Scientific, San Rafael, CA).

\section{Results}

Gastric Juice $\mathrm{PGE}_{2}$

The levels of $\mathrm{PGE}_{2}$ (Fig. 1) in patients with $\mathrm{CAG} / \mathrm{IM} / \mathrm{Ad}$ Ca were over $2,000 \mathrm{pg} / \mathrm{ml}$, i.e. a fivefold elevation, as compared to the controls $(P<0.01)$. When compared to the group with CAG the levels in patients with CAG/IM/ AdCa were about threefolds higher $(P<0.05)$. The levels were also high in patients with CAG/IM, about threefold as compared to the controls. In patients with CAG the levels were almost twofold higher than in controls.

\section{Gastric Juice EGF}

The concentration of EGF (Fig. 2) in gastric secretion of patients with $\mathrm{CAG} / \mathrm{IM} / \mathrm{AdCa}$ was over fourfold higher than the controls $(6.4 \mathrm{ng} / \mathrm{ml}$ vs. $1.6 \mathrm{ng} / \mathrm{ml}, P<0.001)$ and threefold higher in comparison to the CAG group $(P<0.05)$. The levels were also elevated in CAG/IM although to a much lower concentration than those with AdCa, reaching about threefold increase as compared to the controls. The results of EGF in the samples obtained from CAG were about $1 / 3$ higher than in controls.

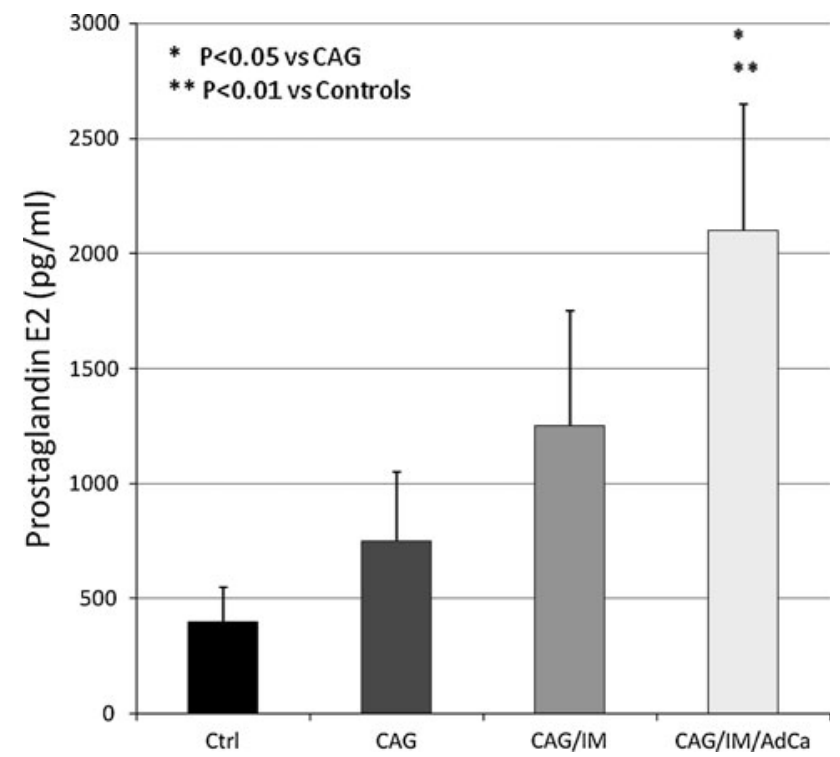

Fig. 1 Gastric Juice prostaglandin E2 in controls (Ctrl), chronic atrophic gastritis $(C A G)$, chronic atrophic gastritis/intestinal metaplasia $(C A G / I M)$, and chronic atrophic gastritis/intestinal metaplasia/ adenocarcinoma (CAG/IM/AdCa)

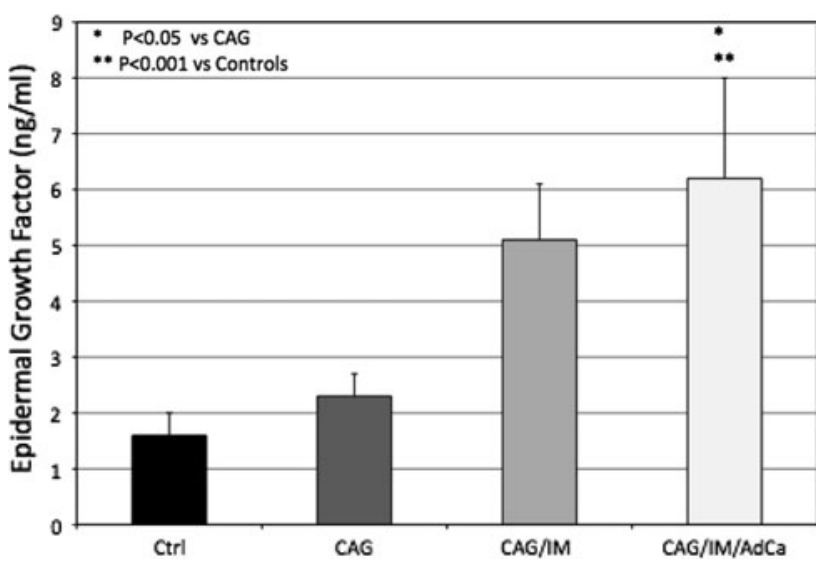

Fig. 2 Gastric juice EGF in controls $(C t r l)$, chronic atrophic gastritis $(C A G)$, chronic atrophic gastritis/intestinal metaplasia $(C A G / I M)$, and chronic atrophic gastritis/intestinal metaplasia/adenocarcinoma $(C A G / I M / A d C a)$

\section{Gastric Juice TGF $\alpha$}

Intriguingly, the levels of TGF $\alpha$ (Fig. 3) in patients with CAG/IM were as low as $1 / 5$ th of the control group or patients with CAG $(P<0.05)$. The levels were as low as $0.07 \mathrm{ng} / \mathrm{ml}$ in this subset of patients. The concentration of TGF $\alpha$ in patients with CAG/IM/AdCa were half the value of controls and CAG $(P<0.05)$, but increased almost threefold from the lowest value recorded in patients with CAG/IM. However the TGF $\alpha$ levels in CAG were quite similar to values in controls. 


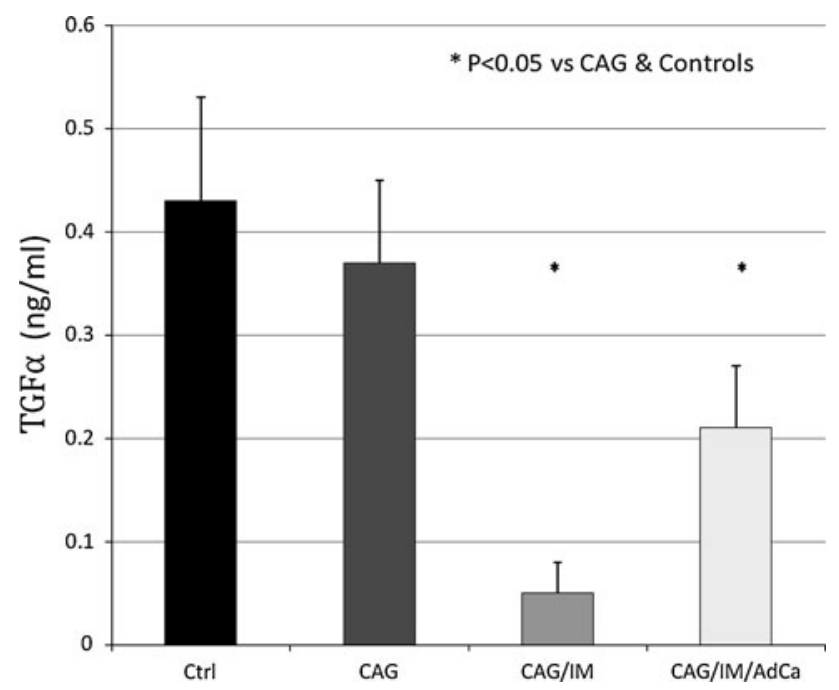

Fig. 3 Gastric juice TGF $\alpha$ in controls $(C t r l)$, chronic atrophic gastritis $(C A G)$, chronic atrophic gastritis/intestinal metaplasia $(C A G / I M)$, and chronic atrophic gastritis/intestinal metaplasia/adenocarcinoma $(C A G / I M / A d C a)$

\section{Discussion}

Chronic inflammation has been well implicated in the etiology of alimentary tract cancer. Key molecular players that link inflammation to carcinogenesis are prostaglandins, cytokines, nuclear factor $-\kappa \mathrm{B}$, chemokines, angiogenic growth factors and free radicals as well as gene products which contribute to multistage of carcinogenesis through activation of oncogenic products and/or inhibition of tumor suppressor genes [13]. Though inflammation includes injury, repair and resolution; all inflammatory cells may also contribute to carcinogenesis [14]. Inflammatory stimuli include chemicals, foreign bodies and infectious organisms such as Helicobacter pylori (Hp), Ebstein Barr virus among others [15].

$H p$ has been linked epidemiologically to gastric and duodenal ulcers, gastric cancer and gastric mucosa-associated lymphoid tissue (MALT) lymphoma [16-18]. Hp induced $\mathrm{CAG}$ is a prerequisite for the formation of preneoplastic and malignant lesions, both in humans and in rodent models of $\mathrm{Hp}$-induced disease [19, 20]. The transformation from normal mucosa to gastric cancer occurs via a sequence of precursor lesions starting with CAG, IM and dysplasia [21].

Inflammation and carcinogenesis share a common molecular mediator, the cyclooxygenase (COX) enzymes COX-1 and COX-2 which generate their major product $\mathrm{PGE}_{2}$, exerting its effects by binding to the ubiquitously expressed the E prostanoid receptors 1-4 [22, 23].

COX-2-dependent pathways play a role in carcinogenesis, especially in the gastrointestinal tract [24, 25]. The long-term low-level intake of nonsteroidal anti- inflammatory drugs inhibiting COX activity reduces the risk of gastric and colorectal cancer [26-28]. Tumorderived $\mathrm{PGE}_{2}$ is believed to promote cancer progression by stimulating cell motility/invasion, angiogenesis and by preventing tumor cell apoptosis [29] through potentiation and induction of target genes by activation of the EGF receptor pathway [30]. $\mathrm{PGE}_{2}$ through its strong immunosuppressive effects, may allow tumors to evade immune surveillance [31].

It is a known fact that COX-1 and COX-2 are widely expressed in gastric cancers resulting in elevated $\mathrm{PGE}_{2}$ levels which up regulates VEGF expression and this effect is mediated by the EGFR activation [32-36]. This enhances the cancer cell invasion and angiogenesis via TLR2 and TLR9, which can be attenuated by the specific COX-2 inhibitor NS398 or celecoxib [37].

Our study clearly substantiates the above concepts of a link between prostaglandin $\mathrm{E}_{2}$ and carcinogenesis. The levels of $\mathrm{PGE}_{2}$ were significantly higher in CAG/IM/AdCa and the levels showed a proportional increase in CAG and CAG/IM. This confirms the findings that $\mathrm{PGE}_{2}$ in the gastric mucosa and plasma is increased in all patients with gastric cancer, especially with metastasis and it correlates well with age, stage, histological pattern of tumor, its differentiation and infiltration [38, 39].

The gastrointestinal tract possesses the remarkable ability to withstand injury resulting in cell migration (restitution), followed by an increase in proliferation and remodeling with at least 30 different peptides being involved in stimulating the repair process. In general peptides can be compartmentalized into: (1) mucosal integrity peptides which are predominantly involved in maintaining mucosal morphology e.g., TGF $\alpha$ (2) luminal surveillance peptides which stimulate proliferation and repair at sites of injury e.g., EGF and (3) rapid response repair peptides whose production is rapidly regulated at sites of injury [40].

EGF, a potent stimulant of proliferation, migration and gut repair is most effective when it can bind to its receptor predominantly located on the basolateral membrane which is easily accessible at the site of injury [41-44]. TGF $\alpha$ is a potent stimulant of proliferation and differentiation acting via the EGF receptor too (EGF-R or c-erb2) [40].

EGF family growth factors including $\mathrm{TGF} \alpha$ have been proposed as integrative cytoprotective factors against gastric injury [37, 45], through stimulation of cell proliferation, migration, inhibition gastric acid secretion and increasing the release of mucus [46-48], which is greatly affected by sialoadenectomy in experimental animals $[49,50]$.

Gastric cancer patients show an increased expression of EGF and TGF $\alpha$ but their gastric acid secretion is markedly reduced possibly due to atrophy of oxyntic mucosa. 
Overexpression of growth factors in gastric mucosa as well as reduced gastric acid secretion due to gastric mucosal atrophy may be implicated in the pathogenesis of gastric cancer [51].

In our study there is a significant increase in the EGF levels which in concordance with the declining levels of TGF $\alpha$ would benefit to detect those transforming from CAG to CAG/IM and eventually to gastric carcinoma. Very high levels of EGF were found in patients with $\mathrm{AdCa}$, almost a fivefold increase in the concentration compared to the two to threefold rise in CAG and CAG/IM.

Our analysis of gastric juice samples also shows the significant reduction in the TGF $\alpha$ level, which confirms the potential cytoprotective value of this growth factor against development of gastric neoplasm in the setting of CAG/IM. Significant reduction in the levels of TGF $\alpha$ in CAG/IM tissue may facilitate its transformation into gastric cancer. This important aspect during the analysis of the gastric juice should be borne in mind in patients with CAG and with very low levels of $\mathrm{TGF} \alpha$, who could be progressing towards IM vis-à-vis AdCa.

From our analysis of gastric juice samples we conclude that a step wise increase in the $\mathrm{PGE}_{2}$ starting from normal and going through phases of CAG, CAG/IM and ultimately to $\mathrm{CAG} / \mathrm{IM} / \mathrm{AdCa}$ provides a good evidence that testing its content in samples aspirated during surveillance endoscopy could be of value in their predictive potential before and during the development of $\mathrm{AdCa}$. This however requires further investigation. In a similar way simultaneously measuring the concentration of growth factors such as EGF and $\mathrm{TGF} \alpha$ will provide us clue as to the underlying disease progression. As noted above in our discussion EGF levels closely parallel the $\mathrm{PGE}_{2}$ levels showing a step wise increase from controls through stages of CAG, CAG/IM and CAG/IM/AdCa. However the levels of TGF $\alpha$ are conversely reduced as the condition progresses from $\mathrm{CAG}$ through CAG/IM and CAG/IM/AdCa thereby concurring with several studies done earlier on its protective values [44, 45].

Although in our study subjects the $H p$ was eradicated prior to the screening endoscopy, it takes several years for most of the patients with CAG to significantly improve the gastric morphology despite eradication. Therefore although our patients had $\mathrm{Hp}$ negative $\mathrm{CAG}, \mathrm{CAG} / \mathrm{IM}$ and CAG/IM/ $\mathrm{AdCa}$ the gastric juice analysis of $\mathrm{PGE}_{2}, \mathrm{EGF}$ and $\mathrm{TGF} \alpha$ still reflect the ongoing chronic inflammatory changes within the gastric mucosa. Hence to eliminate the potential detrimental impact of $H p$ colonization and subsequent development of chronic inflammation leading to no return to the original normal morphology but rather going on to CAG, CAG/IM and the dreaded complication of gastric $\mathrm{AdCa}$ it is highly advisable to treat young people at an early age especially in countries with high endemicity of
$H p$. This is the only way to prevent the potential chronic complications associated with $H p$ the most notable being the gastric AdCa.

In conclusion, testing the gastric juice for EGF, TGF $\alpha$ and $\mathrm{PGE}_{2}$ in patients with endoscopy and biopsy proven $\mathrm{CAG}$, due to $H p$ may be helpful in follow up of these patients who may potentially progress to IM and ultimately to AdCa. This could be considered as an adjunct to histologic assessment especially given the fact that even the best biopsy specimen regimens during surveillance are inherited with significant sampling errors.

\section{Conflict of interest None.}

Open Access This article is distributed under the terms of the Creative Commons Attribution Noncommercial License which permits any noncommercial use, distribution, and reproduction in any medium, provided the original author(s) and source are credited.

\section{References}

1. Goldberg HI, Dodds WJ, Gee S, et al. Role of acid and pepsin in acute experimental esophagitis. Gastroenterology. 1969;56:223-230.

2. Richter JE. The symptom index: correlation of acid reflux with symptoms. In: Richter JE, ed. Ambulatory esophageal pH monitoring. New York: Igaku-Shoin; 1991:93-100.

3. Slomiany BL, Sarosiek J, Slomiany A. Gastric mucus and the mucosal barrier. Dig Dis. 1987;5:125-145.

4. Sarosiek J, Feng T, McCallum RW. The interrelationship between salivary epidermal growth factor and the functional integrity of the esophageal mucosal barrier in the rat. Am J Med Sci. 1991;302:359-363.

5. Sarosiek J, Bilski J, Murty VLN, et al. Role of salivary epidermal growth factor in the maintenance of physicochemical characteristics of oral and gastric mucus coat. Biochem Biophys Res Commun. 1988;152:1421-1427.

6. Sarosiek J, McCallum RW. The evolving appreciation of the role of esophageal mucosal protection in the pathophysiology of gastroesophageal reflux disease. J Pract Gastroenterol. 1994;18: 20J-20Q

7. Rourk RM, Namiot Z, Sarosiek J, et al. Diminished content of esophageal epidermal growth factor in patients with reflux esophagitis. Am J Gastroenterol. 1994;89:1177-1184.

8. Rourk RM, Namiot Z, Sarosiek J, et al. Impairment of salivary epidermal growth factor secretory response to esophageal mechanical and chemical stimulation in patients with reflux esophagitis. Am J Gastroenterol. 1994;89:237-244.

9. Sarosiek J, Jensen TJ, Maton PN, et al. Gastric salivary epidermal growth factor in patients with Zollinger-Ellison syndrome: its protective potential. Am J Gastroenterol. 2000;95:1158-1165.

10. Kelly RW, Graham BJM, O'Sullivan MJ. Measurement of PGE2 as the methyl oximate by the radioimmunoassay using a novel iodinated label. Prostagland Leukotrienes Essential Fatty Acids. 1989;89:588-594.

11. Sarosiek J, Yu Z, Namiot Z, et al. Impact of acid and pepsin on human esophageal prostaglandins. Am J Gastroenterol. 1994;89: 588-594.

12. Marcinkiewicz M, Sarosiek J, Edmunds MC, et al. Monophasic luminal release of prostaglandin E2 in patients with reflux esophagitis under the impact of acid and acid/pepsin solutions: its 
potential pathogenetic significance. J Clin Gastroenterol. 1995; 21:268-274.

13. Kim YJ, Chung JW, Lee SJ, et al. Progression from chronic atrophic gastritis to gastric cancer; tangle, toggle, tackle with Korea red ginseng. J Clin Biochem Nutr. 2010;46:195-204.

14. Oshima H, Tazawa H, Sylla BS, Sawa T. Prevention of human cancer by modulation of chronic inflammatory process. Mutat Res. 2005;591:110-122.

15. Coussens L, Werb Z. Inflammation and cancer. Nature. 2002; 420:860-867.

16. Parsonnet J, Friedman GD, Vandersteen DP, et al. Helicobacter pylori infection and the risk of gastric carcinoma. $N$ Engl J Med. 1991;325:1127-1131.

17. Parsonnet J, Isaacson PG. Bacterial infection and MALT lymphoma. N Engl J Med. 2004;350:213-215.

18. Danesh J. Helicobacter pylori infection and gastric cancer: systematic review of the epidemiological studies. Aliment Pharmacol Ther. 1999;13:851-856.

19. Fox JG, Sheppard BJ, Dangler CA, et al. Germ-line p53-targeted disruption inhibits Helicobacter-induced premalignant lesions and invasive gastric carcinoma through down-regulation of Th1 proinflammatory responses. Cancer Res. 2002;62:696-702.

20. Rieder G, Merchant JL, Haas R. Helicobacter pylori cag-type IV secretion system facilitates corpus colonization to induce precancerous conditions in Mongolian gerbils. Gastroenterology. 2005;128:1229-1242.

21. Correa P. Helicobacter pylori and gastric carcinogenesis. Am J Surg Pathol. 1995;19:S37-S43.

22. Simmons DL, Botting RM, Hla T. Cyclooxygenase isozymes: the biology of prostaglandin synthesis and inhibition. Pharmacol Rev. 2004;56:387-437.

23. Narumiya S, Sugimoto Y, Ushikubi F. Prostanoid receptors: structures, properties, and functions. Physiol Rev. 1999;79: $1193-1226$.

24. Potter JD, Ulrich CM. COX-2 and gastric cancer: more on inflammation and neoplasia. Gastroenterology. 2006;130:2198-2200.

25. Liu F, Pan K, Zhang X, et al. Genetic variants in cyclooxygenase2: expression and risk of gastric cancer and its precursors in a Chinese population. Gastroenterology. 2006;130:1975-1984.

26. Ulrich CM, Bigler J, Potter JD. Non-steroidal anti-inflammatory drugs for cancer prevention: promise, perils and pharmacogenetics. Nat Rev Cancer. 2006;6:130-140.

27. Kune GA, Kune S, Watson LF. Colorectal cancer risk, chronic illnesses, operations, and medications: case control results from the Melbourne Colorectal Cancer Study. Cancer Res. 1988; 48:4399-4404.

28. Wang WH, Huang JQ, Zheng GF, et al. Non-steroidal antiinflammatory drug use and the risk of gastric cancer: a systematic review and meta-analysis. J Natl Cancer Inst. 2003;95:1784-1791.

29. Wang D, DuBois RN. Inflammatory mediators and nuclear receptor signaling in colorectal cancer. Cell Cycle. 2007;6:682-685.

30. Cha YI, Dubois RN. NSAIDs and cancer prevention: targets downstream of COX-2. Annu Rev Med. 2007;58:239-252.

31. Pockaj BA, Basu GD, Pathangey LB, et al. Reduced T-cell and dendritic cell function is related to cyclooxygenase- 2 overexpression and prostaglandin E2 secretion in patients with breast cancer. Ann Surg Oncol. 2004;11:328-339.

32. Jang TJ. Expression of proteins related to prostaglandin E2 biosynthesis is increased in human gastric cancer, during gastric carcinogenesis. Virchow's Arch. 2004;445:564-571.

33. Rigas B, Goldman IS, Levine L. Altered eicosanoid levels in human colon cancer. J Lab Clin Med. 1993;122:518-523.
34. Bennett A, Civier A, Hensby CN, Melhuish PB, Stamford IF. Measurement of arachinodate and its metabolites extracted from human normal and malignant gastrointestinal tissues. Gut. 1987; 28:315-318.

35. McLemore TL, Hubbard WC, Litterst CL, et al. Profiles of prostaglandin biosynthesis in normal lung and tumor tissue from lung cancer patients. Cancer Res. 1998;58:3140-3147.

36. Ding Y-B, Shi R-H, Tong J-D, et al. PGE2 up-regulates vascular endothelial growth factor expression in MKN28 Gastric cancer cells via epidermal growth factor receptor signalling system. Exp Oncol. 2005;27:108-113.

37. Nakajima T, Konda Y, Izumi Y, et al. Gastrin stimulates the growth of gastric pit cell precursors by inducing its own receptors. Am J Physiol Gastrointest Liver Physiol. 2002;282:G359G366.

38. Fu QL, Yang MF, Li ZJ, et al. Prostaglandin E (PGE), gastric carcinoma. Zhonghua Zhong Liu Za Zhi. 1986;8:345-348.

39. Kushlinkskiǐ NE, Klimenkov AA, Abdraimov SB, Rommenberg VI, Liakina LT. Prostaglandins E in malignant stomach neoplasms. Vopr Onkol. 1994;40:171-176.

40. Playford RJ, Wright NA, Marchbank T. Endogenous peptides and peptide therapy in gut defense and repair. Drug News Perspect. 2000;13:330.

41. Wright NA, Pike C, Elia G. Induction of a novel epidermal growth factor-secreting cell lineage by mucosal ulceration in human gastrointestinal stem cells. Nature. 1990;343:82-85.

42. Playford PJ, Harby A, Gschmeissner S, Peiffer LP, McGarrity T, Wright NA. The epidermal growth factor receptor (EGF-R) is present on the basolateral, but not the apical surface of the enterocytes in the human gastrointestinal tract. Gut. 1996;38:303-305.

43. Sarosiek J, Feng T, McCallum RW. The interrelationship between salivary epidermal growth factor and the functional integrity of the esophageal mucosal barrier in the rat. Am J Med Sci. 1991;302:359-363.

44. Playford RJ, Wright NA. Why is EGF present in the gut lumen? Gut. 1996;38:303-305.

45. Barnard JA, Beauchamp RD, Russell WE, Dubois RN, Coffey RJ. Epidermal growth factor-related peptides and their relevance to gastrointestinal pathophysiology. Gastroenterology. 1995;108: 564-580.

46. Ciacci C, Lind SE, Podolsky DK. Transforming growth factor beta regulation of migration in wounded rat intestinal epithelial monolayers. Gastroenterology. 1993;105:93-101.

47. Konturek JW, Bielanski W, Konturek SJ, Bogdal J, Olesky J. Distribution and release of epidermal growth factor in man. Gut. 1989;30:1194-1200.

48. Konturek SJ, Brzozowski T, Majka J, Dembinski A, Slomiany A, Slomiany BL. Transforming growth factor alpha and epidermal growth factor in protection and healing of gastric mucosal injury. Scand J Gastroenterol. 1992;27:649-655.

49. Skov Olsen P, Poulsen SS, Therkelsen K, Nex E. Effect of sialoadenectomy and synthetic human urogastrone on healing of chronic duodenal ulcers in rats. Gut. 1986;27:1443-1449.

50. Konturek SJ, Dembinski A, Warzecha Z, Brzozowski T, Gregory $\mathrm{H}$. Role of epidermal growth factor in healing of chronic gastroduodenal ulcers in rats. Gastroenterology. 1988;94:1300-1307.

51. Konturek PC, Bielanski W, Konturek SJ, Hahn EG. Gastric mucosal expression and luminal release of growth factors in gastric carcinoma and duodenal ulcer patients before and after eradication of helicobacter pylori. J Physiol Pharmacol. 1997;48: 375-382. 